\title{
TU/e emonowne

\section{System peaks in capillary zone electrophoresis : what are they and where are they coming from?}

\section{Citation for published version (APA):}

Beckers, J. L., \& Everaerts, F. M. (1997). System peaks in capillary zone electrophoresis : what are they and where are they coming from? Journal of Chromatography, A, 787(1-2), 235-242. https://doi.org/10.1016/S00219673(97)00612-2

DOI:

10.1016/S0021-9673(97)00612-2

Document status and date:

Published: 01/01/1997

\section{Document Version:}

Publisher's PDF, also known as Version of Record (includes final page, issue and volume numbers)

\section{Please check the document version of this publication:}

- A submitted manuscript is the version of the article upon submission and before peer-review. There can be important differences between the submitted version and the official published version of record. People interested in the research are advised to contact the author for the final version of the publication, or visit the $\mathrm{DOI}$ to the publisher's website.

- The final author version and the galley proof are versions of the publication after peer review.

- The final published version features the final layout of the paper including the volume, issue and page numbers.

Link to publication

\section{General rights}

Copyright and moral rights for the publications made accessible in the public portal are retained by the authors and/or other copyright owners and it is a condition of accessing publications that users recognise and abide by the legal requirements associated with these rights.

- Users may download and print one copy of any publication from the public portal for the purpose of private study or research.

- You may not further distribute the material or use it for any profit-making activity or commercial gain

- You may freely distribute the URL identifying the publication in the public portal.

If the publication is distributed under the terms of Article 25fa of the Dutch Copyright Act, indicated by the "Taverne" license above, please follow below link for the End User Agreement:

www.tue.nl/taverne

Take down policy

If you believe that this document breaches copyright please contact us at:

openaccess@tue.nl

providing details and we will investigate your claim. 


\title{
System peaks in capillary zone electrophoresis What are they and where are they coming from?
}

\author{
J.L. Beckers*, F.M. Everaerts \\ Eindhoven University of Technology, Laboratory of Instrumental Analysis, P.O. Box 5135600 MB Eindhoven, Netherlands
}

Received 28 February 1997; received in revised form 22 April 1997; accepted 29 May 1997

\begin{abstract}
If zones do not contain any sample ionic species and contain only ionic species of the background electrolyte (BGE) with a composition, however, different from that of the BGE with regard to the concentrations of these ionic species and/or the $\mathrm{pH}$ in the zone, they can migrate with a specific mobility through the BGE. Of course, these BGE-like peaks will only be visible in electropherograms if the ionic species of the BGE can be observed by the detector. In this paper we propose to apply the term system peaks exclusively for BGE-like peaks and a model is given for the calculation of the mobilities of such system peaks. These system peaks can be created by directly introducing BGE-like zones with a composition different from the BGE or can be induced by the injection of a sample or even water. Several examples of system peaks are given. (C) 1997 Elsevier Science B.V.
\end{abstract}

Keywords: System peaks; Background electrolyte

\section{Introduction}

Dynamic electrophoretic processes can be described with some rather simple mathematical equations under the assumption that at each point in space and time Ohm's law and the electroneutrality condition are valid and all mass balances must be obeyed. The electrophoretic compartment can be divided in small segments and all parameters of a segment can be calculated from the parameters of a foregoing segment solving the mathematical equations, starting from the composition of the background electrolyte (BGE). Generally single values for the $\mathrm{pH}, E$ and concentrations of co- and counter ions are obtained whereby all equations are satisfied. The velocity of a sample segment can be calculated

*Corresponding author. from the values of the mobility of the sample segment and the local $E$. If the velocity of a sample segment is higher than the velocity of the sample ions in the BGE, the sample peak is tailing otherwise fronting and with the mathematical model all peak characteristics can be calculated even for BGEs with more co- and counter ionic species [1-4]. All calculated peak characteristics can be visualized in so- called SystCharts [4]. In SystCharts of BGEs with more than one co- and counter ionic species discontinuities in several relationships were present at a sample mobility equal to that of already earlier described system peaks [5] for BGEs with two coions.

In this paper we will discuss the questions 'what are system peaks?' and 'where are they coming from?'. A mathematical model will be described for the calculation of the mobilities of such system peaks 
and several examples of system peaks will be discussed.

\section{Theory}

\subsection{What can be understood by the term system peaks?}

In literature system peaks are often referred to [6-10] although the concept of system peaks is scarcely defined and authors apply the term differently. Disturbances in the basic signal of a detector can be caused by a variety of effects. Often adsorbed ionic species can be released from the capillary wall and can migrate through the electrolyte system especially on changing of $\mathrm{BGE}$ or the direction of the applied current. If these components are detected, irreproducible disturbances in the detector trace are present in the electropherogram. These peaks are not really system peaks, but can better be called ghost peaks. We will apply the term system peaks if peaks are considered, present in an electropherogram, which correlate with zones that do not contain any sample ionic species and contain only ionic species of the BGE, with a composition, however, different from that of the BGE with respect to the concentrations of the ionic species and/or the $\mathrm{pH}$. In that case, generally more peaks are present in an electropherogram than can be expected from the number of sample ions present in a sample or even peaks are present without injection of sample components or just injecting water. Of course these peaks are only visible in the electropherograms if the detector can register these BGE-like zones.

If such a system peak has been registered by e.g., a UV detector, at least one of the co- or counter ionic species must be present at an increased or decreased concentration level in the system peak compared with the composition of the BGE. The question is how this can occur. As will be shown such a situation will appear if a BGE-like zone is injected or induced by the injection of a sample solution.

For a discussion of the latter case, we reconsider the relationships between the calculated concentrations of the two co-ions potassium and histidine in a sample peak versus the mobility of the sample ions at infinite dilution. In Fig. 1 these relationships are shown for a sample component segment of $5 \cdot 10^{-4}$ $M$, applying a BGE consisting of a mixture of 0.005 $M$ potassium and $0.005 M$ histidine adjusted to $\mathrm{pH} 5$ by adding acetic acid, calculated with a model

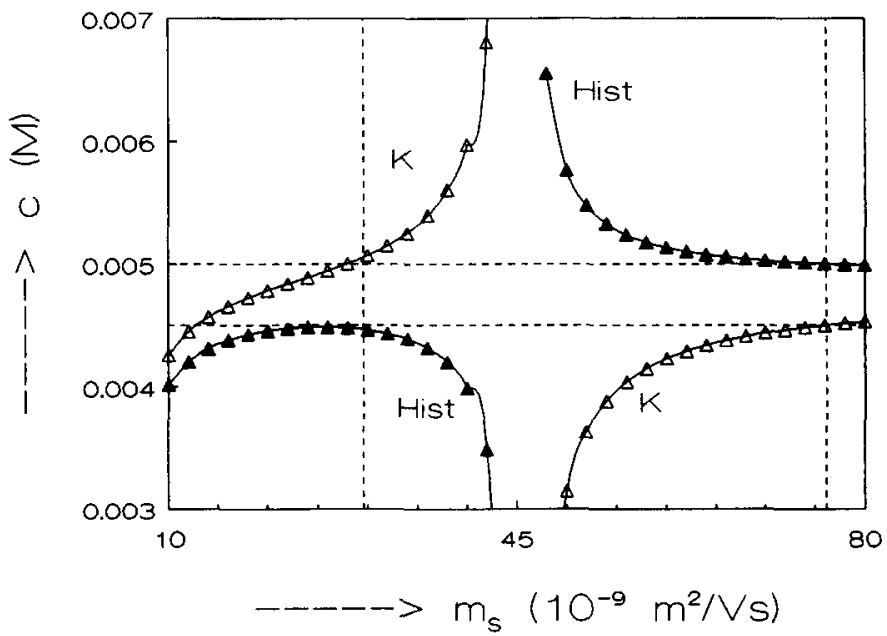

Fig. 1. Calculated relationships between the concentrations of the two co-ions potassium (K) and histidine (Hist) in a sample zone with a sample concentration of $5 \cdot 10^{-4} M$ versus the ionic mobilities at infinite dilution $\left(m_{\mathrm{S}}\right)$ of sample cations with a $\mathrm{pK}$ value of 14 for a BGE consisting of a mixture of $0.005 \mathrm{M}$ potassium and $0.005 \mathrm{M}$ histidine adjusted to $\mathrm{pH} 5$ by adding acetic acid. The vertical dashed lines indicate the mobilities at infinite dilution of the two co-ions. The horizontal dashed lines indicate the concentrations of the co-ions in the BGE $(0.005 M)$ and the value for a one-to-one displacement of a co-ion $(0.0045 M)$. For further information see text. 
described in Ref. [3]. If the mobility of the sample ions equals that of one of the co-ions (vertical dashed lines) a selective displacement takes place [11] and the concentrations of the co-ions are respectively $0.005 M$ and $0.0045 M$ (horizontal dashed lines). As can be seen there is a discontinuity in the relationships at a mobility of the sample ionic species of $\sim 46 \cdot 10^{-9} \mathrm{~m}^{2} \mathrm{~V}^{-1} \mathrm{~s}^{-1}$. For sample ionic species with a mobility in-between this value and the mobility of the co-ion $\mathrm{K}^{+}$, the potassium concentration strongly decreases and the concentration of histidine strongly increases in the sample zone and v.v. for sample zones with a mobility in-between this value and the mobility of the co-ion histidine. This means that UV transparent sample ions with a mobility higher than $46 \cdot 10^{-9} \mathrm{~m}^{2} \mathrm{~V}^{-1} \mathrm{~s}^{-1}$ are positive peaks in the electropherograms (histidine is a UV absorbing co-ion) and with mobilities lower than $\sim 46 \cdot 10^{-9} \mathrm{~m}^{2} \mathrm{~V}^{-1} \mathrm{~s}^{-1}$ are dips.

If in a sample zone with a mobility higher than $\sim 46 \cdot 10^{-9} \mathrm{~m}^{2} \mathrm{~V}^{-1} \mathrm{~s}^{-1}$ the histidine concentration is higher and the potassium concentration is lower than those in the BGE, somewhere in the capillary tube a BGE-like plug must be induced with an increased potassium concentration and a decreased histidine concentration, i.e. if the sample appears as a positive peak in the electropherogram there is a BGE-like zone which is a dip and v.v. for sample mobilities lower than $\sim 46 \cdot 10^{-9} \mathrm{~m}^{2} \mathrm{~V}^{-1} \mathrm{~s}^{-1}$, as already observed [5]. This effect is very strong if the sample mobility approaches the value of $\sim 46 \cdot 10^{-9}$ $\mathrm{m}^{2} \mathrm{~V}^{-1} \mathrm{~s}^{-1}$, through which the sample peak area and system peak area strongly increase or decrease respectively. If these induced $B G E-l i k e$ peaks are really the observed system peaks (SPs) in the electropherograms of Refs. [3,5], all these BGE-like peaks should migrate with about the same mobility equal to the value of the mobility of the discontinuity in Fig. 1 and these values must be independent on the kind of sample solution injected. To prove this, a mathematical model must be set up to calculate the mobility of BGE-like peaks. In fact such a model already has been used for a BGE with a single coand counter ion [5] where it has been found that the basic equations only could be solved assuming that the BGE-like zone should migrate with a particular mobility. For the calculation of BGE-like zones in BGEs with more co- and/or counter ionic species the general model for the calculation of the parameters in sample zones [4] is adapted for the calculation of all parameters in BGE-like zones (see appendix for this model). With this model we calculated the mobilities for BGE-like zones with varying composition applying BGEs consisting of two co-ions potassium and histidine with different concentrations adjusted to $\mathrm{pH}$ of 5 by adding acetic acid (the sum of the concentrations of the co-ions is always $0.01 \mathrm{M}$ ). All mobilities at infinite dilution and the $\mathrm{p} K$ values of ionic species used in the calculations are given in Table 1. In Table 2 the calculated mobilities of BGE-like zones are given. Because this model fails for the calculation of the mobility of the BGE-like zone identical to that of the BGE, the calculations are carried out for BGE-like zones with assumed concentrations of potassium respectively higher and lower than that in the BGE. As can be seen from Table 2, the calculated mobilities for all BGE-like zones in a particular BGE are, indeed, nearly equal and e.g. for a BGE of $0.005 M$ potassium-0.005 $M$ histidine equal to $\sim 41.30 \cdot 10^{-9} \mathrm{~m}^{2} \mathrm{~V}^{-1} \mathrm{~s}^{-1}$. In Fig. 1 the mobility of the discontinuity was $\sim 46 \cdot 10^{-9}$ $\mathrm{m}^{2} \mathrm{~V}^{-1} \mathrm{~s}^{-1}$, calculated however for mobilities at infinite dilution. Recalculated for the applied ionic strength it is $\sim 41.8 \cdot 10^{-9} \mathrm{~m}^{2} \mathrm{~V}^{-1} \mathrm{~s}^{-1}$ and the adapted model seems to produce useful values. For a second check of the model we calculated also in the same way all values of the mobilities of SPs for BGEs consisting of mixtures of potassium and imidazole as co-ions with a total cationic concentration of $0.01 \mathrm{M}$ adjusted to a pH of 5 by adding acetic acid and compared the calculated values with the measured values as given in Ref. [5]. For these comparison, all migration times are corrected for the ramp time of 0.17 min using the Beckman P/ACE

Table 1

Ionic mobilities at infinite dilution, $m\left(\mathrm{~m}^{2} \mathrm{~V}^{-1} \mathrm{~s}^{-1}\right)$ and $\mathrm{p} K$ values for ionic species used in the calculations

\begin{tabular}{lcc}
\hline Ionic species & $m \cdot 10^{4}$ & $\mathrm{pK}$ \\
\hline Acetic acid & -42.4 & 4.76 \\
Formic acid & -56.6 & 3.75 \\
Histidine & 29.7 & 6.03 \\
Imidazole & 50.4 & 6.953 \\
Potassium & 76.2 & 14.0 \\
Sodium & 51.9 & 14.0 \\
TEA & 32.5 & $>9.0$ \\
\hline
\end{tabular}


Table 2

Calculated mobilities for BGE-like zones

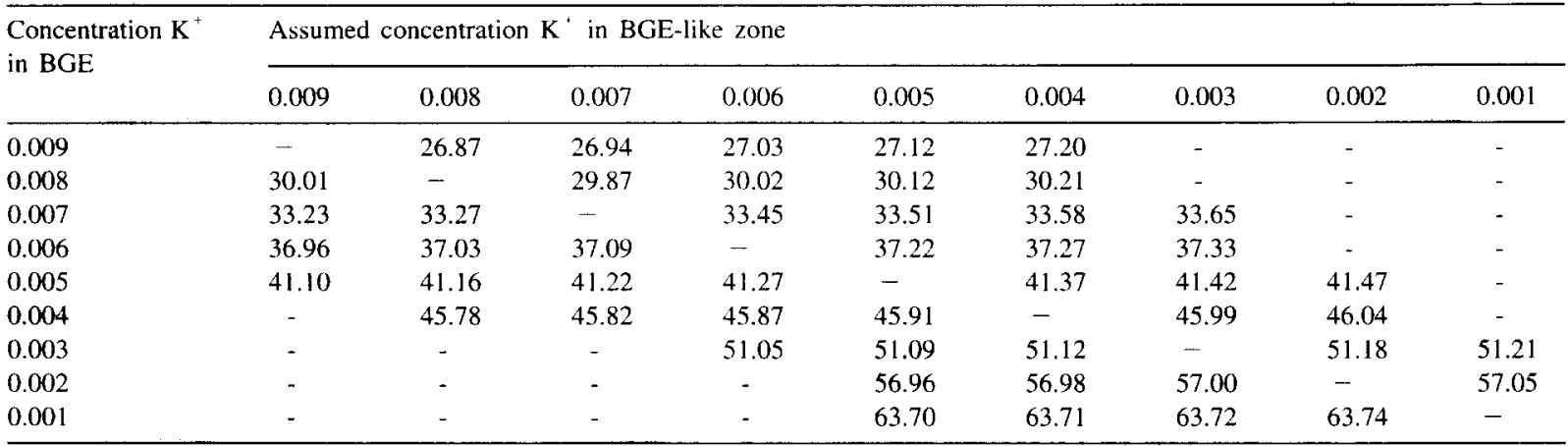

BGEs containing both the two co-ions $\mathrm{K}^{+}$and histidine at a total concentration of $0.01 \mathrm{M}$, adjusted to pH 5 by adding acetic acid were applied.

The composition of the BGE and of the BGE-like zone are indicated by the concentration of the $\mathrm{K}^{+}$ions.

[12] for the calculations of the measured mobilities. The calculated and measured values for all BGEs are shown in Fig. 2 and the agreement is quite impres-

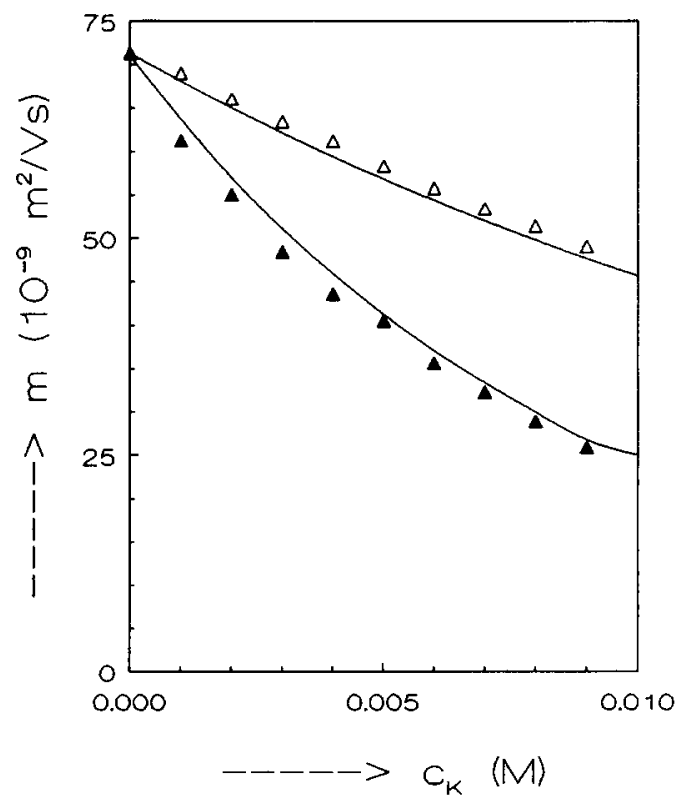

Fig. 2. Relationships between the calculated values (solid line) and measured values for the mobilities of system peaks for BGEs with $(\Delta)$ the two co-ions potassium and histidine and $(\triangle)$ the two co-ions potassium and imidazole respectively. The total cationic concentration of the BGE was always $0.01 M$ and the $\mathrm{pH}$ was adjusted to 5 by adding acetic acid. The concentration of the $\mathrm{K}$ ' ions in the BGEs is indicated on the $x$-axis. For further information see text. sive. Further calculations have been carried out for BGEs consisting of three co-ions and indeed in that case two values could been obtained for the mobilities of two SPs. From the foregoing it appears that the conclusion may be drawn that system peaks are moving BGE-like zones. In results and discussion we will consider several examples of SPs.

\section{Experimental}

For all CZE experiments a P/ACE System 5000 HPCE (Beckman, Fullerton, CA, USA) was used. All experiments were carried out with a Beckman eCAP capillary tubing with a total length of $57.0 \mathrm{~cm}$ and a distance between injection and detection of $50.0 \mathrm{~cm} \times 75 \mu \mathrm{m}$ I.D. The wavelength of the UV detector was set at $214 \mathrm{~nm}$. All experiments were carried out in the cationic mode applying a constant voltage of $15 \mathrm{kV}$, unless stated otherwise, and the operating temperature was $25^{\circ} \mathrm{C}$. Sample introduction was performed by applying pressure injection, where a 1-s pressure injection represents an injected volume of $\sim 4 \mathrm{nl}$. Data analysis was performed using the laboratory-written data analysis program CAESAR.

\section{Results and discussion}

In the section theory it is concluded that SPs are 
BGE-like peaks and we now will consider some examples of SPs in electropherograms. The most simple way to create BGE-like peaks is to inject BGE-like zones and according to the theory considered, a part of this peak will migrate through the system as a SP with a particular mobility determined by composition and $\mathrm{pH}$ of the BGE. From Ref. [5] it is known that the mobilities of the SPs are higher at a low concentration of the BGE and low $\mathrm{pH}$ values. For that reason we injected several BGE-like zones in a BGE consisting of $0.005 \mathrm{M}$ imidazole adjusted at $\mathrm{pH} 3.75$ by adding formic acid. In Fig. 3A the measured electropherograms are given for 5-s pressure injections of $0.004 M$ imidazole formate at $\mathrm{pH}$ (a) 4.25 and (b) 3.25 and of $0.006 \mathrm{M}$ imidazole formate at $\mathrm{pH}$ (c) 4.25 and (d) 3.25 respectively. In (a) the $\mathrm{pH}$ of the sample was 4.25 and because the concentration of the hydrogen ions and of the imidazole is much lower than that in the BGE, the electric field strength is higher in the sample plug, resulting in a high mass flow of imidazole out of the original sample zone. In this way a moving positive $\mathrm{SP}$ is created. In (b) the $\mathrm{pH}$ in the sample plug was 3.25 , i.e. the electric field strength in the sample plug was lower than that in the BGE. The mass flow of imidazole out of the sample plug into the BGE is so low that a negative SP migrates through the system with equal mobility as in (a) and on the spot of the EOF a imidazole peak is present although the original concentration is $0.004 \mathrm{M}$, i.e. that a negative EOF dip according to Kohlrausch's law could be expected. In (c) there is a high mass-flow from the sample plug into the BGE creating a positive SP and the remaining concentration at the spot of the EOF is lower than in (d) where the mass-flow to the BGE is

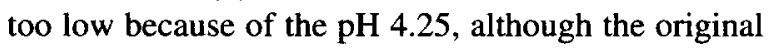
sample concentration is $0.006 \mathrm{M}$. Note that not the complete injected BGE-like zone migrates through the system, but splits in a moving part, the SP, and the other part moves with the EOF. If a sample component is injected with an ionic strength different from that of the BGE, the concentration of the BGE on the spot of injection will be adapted to the original $\omega$ value on the spot of injection according to Kohlrausch's law. Such peaks can be present as dips (low concentration of the sample) or peaks in the electropherogram and can be used as EOF marker. In fact a BGE-like zone is induced and these zones
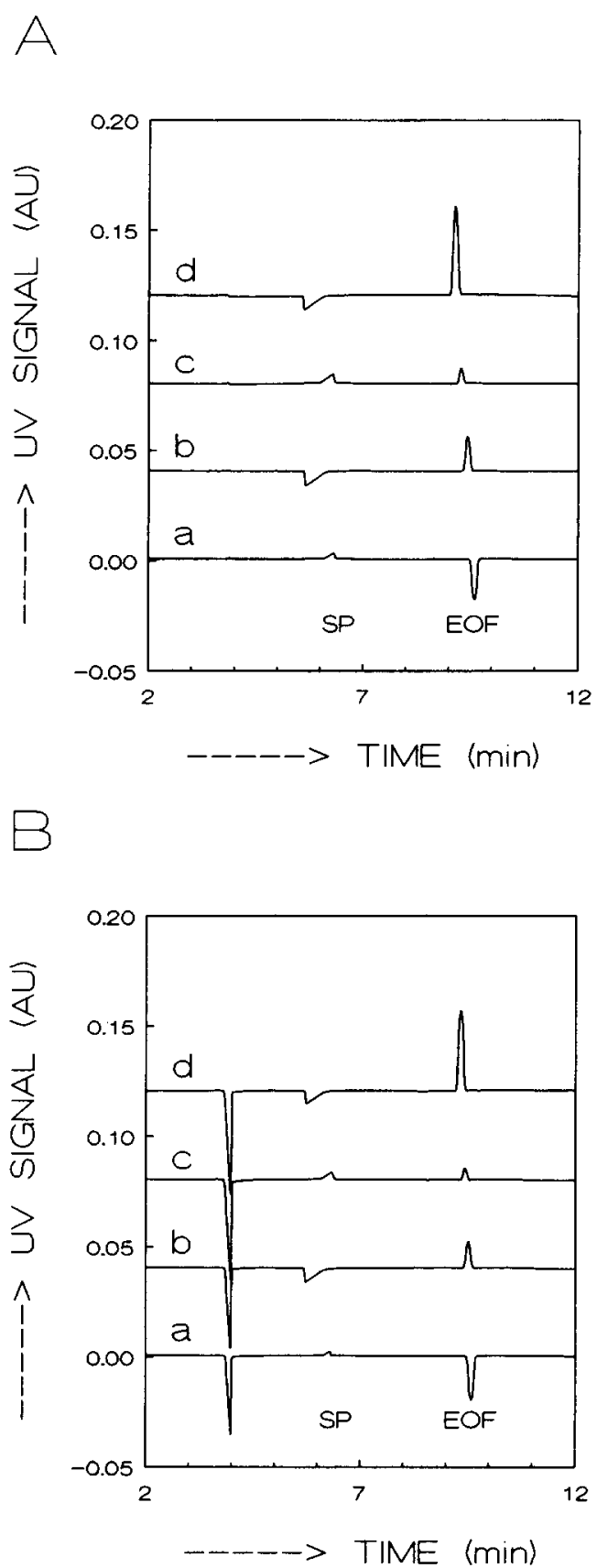

Fig. 3. Measured electropherograms applying a BGE consisting of $0.005 M$ imidazole adjusted to a $\mathrm{pH}$ of 3.75 by adding formic acid for 5-s pressure injections of (A) BGE-like zones consisting of $0.004 M$ imidazole formate at $\mathrm{pH}$ (a) 4.25 and (b) 3.25 and of $0.006 \mathrm{M}$ imidazole formate at $\mathrm{pH}$ (c) 4.25 and (d) 3.25 and (B) for the same concentrations and $\mathrm{pH}$ of sodium formate. 
must have the same properties as injected BGE-like zones. To check this we injected in the same BGE, sample zones of sodium formate with the same $\mathrm{pH}$ and concentrations as of the imidazole formate in Fig. 3A. The measured electropherograms are given in Fig. 3B. The electropherograms of Fig. 3B are identical with Fig. 3A, except for the sodium dip. In fact, sodium migrates away from the injection spot, creating an identical BGE-like zone, resulting in identical SP peaks and dips. As can be seen from Fig. 3, the mobility of the SP is nearly constant for all cases and was $-20 \cdot 10^{-9} \mathrm{~m}^{2} \mathrm{~V}^{-1} \mathrm{~s}^{-1}$ calculated from the diffuse edge of the SP. Calculated with our model a mobility of $\sim 22 \cdot 10^{-9} \mathrm{~m}^{2} \mathrm{~V}^{-1} \mathrm{~s}^{-1}$ was found. Remember that applying BGEs with higher $\mathrm{pH}$ values, the mobility of the SPs are practically zero and no SPs will be present in the electropherograms.

Often SPs are visible in electropherograms applying BGEs with more co- and counter ionic species. For BGEs with two co-ions $\mathrm{K}^{+}$and histidine calculated values are given in Fig. 2 and Table 2. In Fig. 4

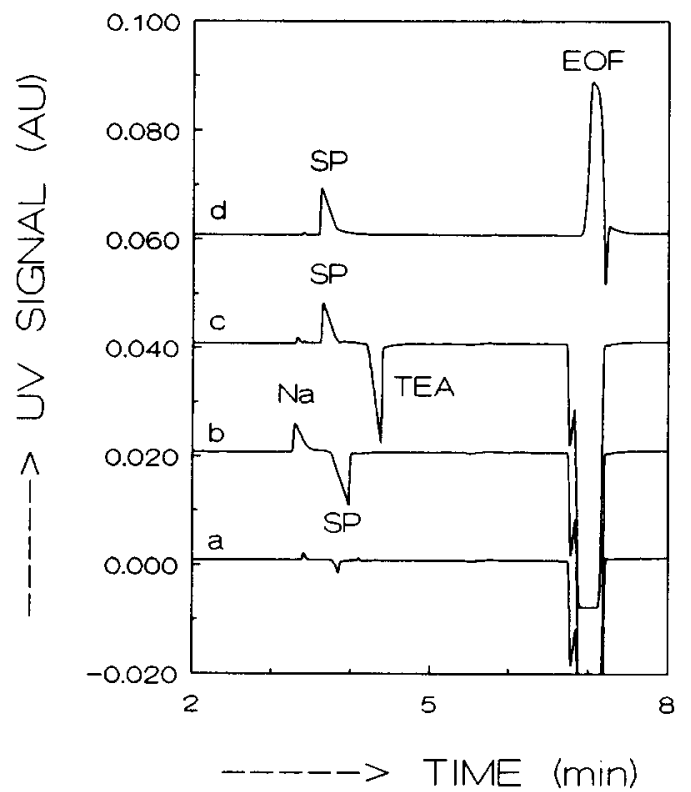

Fig. 4. Measured electropherograms applying a BGE consisting of a mixture of $0.005 \mathrm{M}$ potassium and $0.005 \mathrm{M}$ histidine adjusted to $\mathrm{pH} 5$ by adding acetic acid for 10 -s pressure injections of (a) double distilled water, (b) $0.0005 M \mathrm{Na}^{+}$, (c) $0.0005 M$ TEA and (d) a BGE-like zone consisting of $0.0075 M$ histidine acetate and $0.0025 M$ potassium acetate at $\mathrm{pH}$. measured electropherograms are given, applying a BGE consisting of a mixture of $0.005 M$ potassium ions and $0.005 M$ histidine adjusted to $\mathrm{pH} 5$ by adding acetic acid for $10 \mathrm{~s}$ pressure injections of (a) water, (b) $0.0005 \mathrm{M} \mathrm{Na}^{+}$, (c) $0.0005 \mathrm{M}$ TEA and (d) a BGE-like zone consisting of $0.0075 M$ histidine acetate and $0.0025 M$ potassium acetate at $\mathrm{pH} 5$. In Fig. 4(b) sodium with a mobility higher than that of the SP (see Fig. 1) is a peak because the histidine concentration is larger than in the BGE and a negative SP is induced. This SP correlates with the presence of two co-ions in the BGE. Note there is a second SP with a very small mobility, owing to the $\mathrm{pH} 5$ of the BGE, just for the huge EOF dip! TEA is a negative dip in Fig. 4(c) because its mobility is lower than that of the SP and in the SP an increased concentration of histidine is induced. Injection of a BGE-like zone with high histidine concentration results in a positive SP in Fig. 4(d). The injection of 'pure' water results in a very small sodium peak and small negative SP in Fig. 4(a). All SPs migrate with equal mobilities. The average experimentally obtained values of $\sim 41 \cdot 10^{-9} \mathrm{~m}^{2} \mathrm{~V}^{-1} \mathrm{~s}^{-1}$ agree well with the calculated value (see Table 2 ) of about $41.2 \cdot 10^{-9} \mathrm{~m}^{2} \mathrm{~V}^{-1} \mathrm{~s}^{-1}$. Also the fronting and tailing character can be deduced from the calculated ratio $E_{1} / E_{2}$.

\section{Conclusion}

If BGE-like zones, i.e. zones containing only ionic species of the BGE but with differences in concentrations and/or $\mathrm{pH}$, are injected or induced in BGE system, these zones migrate with a mobility determined by the composition and $\mathrm{pH}$ of the BGE. It is recommended to apply the term system peak exclusively for these BGE-like peaks to distinguish them from other effects causing disturbances in the base-line of the detector trace. If the ionic species of the BGE cannot be registered by the detector no disturbances are present in the electropherograms but even then BGE-like zones with differences in composition and $\mathrm{pH}$ can be present in the separation capillary tube, which can disturb the separation procedure.

In fact, this paper is a continuation of a series of papers about the calculation of parameters in CZE 
zones by a repeated application of a steady-state model [1-4]. Recently, some authors presented interesting contributions to the discussion of system peaks and their origin $[13,14]$ and vacancy electrophoresis [15]. At present we are studying whether the vacancy peaks are identical with the system peaks described and calculated in this paper.

\section{Acknowledgements}

The authors greatly appreciate the loan of the P/ACE 5000 HPCE from Beckman Instruments B.V. (Netherlands).

\section{Appendix 1}

\section{Calculation of the mobility of BGE-like zones}

All equations for both the principle of the electroneutrality, Ohm's law and the mass balances of the co- and counter-ions are exactly as described in Ref. [4]. In Ref. [4] the parameters in a sample zone are calculated and in that case the concentration of the sample ionic species in a particular segment is assumed whereby the velocity of the concerning sample segment $i$ is determined by the product of the mobility of the sample ions, $m_{\mathrm{S}, \mathrm{i}}$, and the local electric field strength $E_{\mathrm{i}}$. For the calculation of the parameters in BGE-like zones the concentration of one of the co-ions is assumed. For the mobility of a BGE-like zone a value $m_{\mathrm{X}}$ is assumed which is calculated from the mass balance of one of the co-ions. The mass balances can be derived from Fig. $5 \mathrm{~A}$ for the co-ions $\mathrm{A}$ and from Fig. $5 \mathrm{~B}$ for the counter ions $C$ as described in Ref. [4]. In the derivation of the mass balances, the notation $m$ refers to the absolute values of the effective mobilities of the ionic components.

\section{Mass balance of the co-ions}

The velocity of the zone boundary between the two segments 1 and 2 is $E_{2} m_{\mathrm{x}}$ and it moves in a unit of time from point 1 at time $t=0$ (see Fig. 5A) to point 3 at time $t=1$. The co-ions A present at point 2
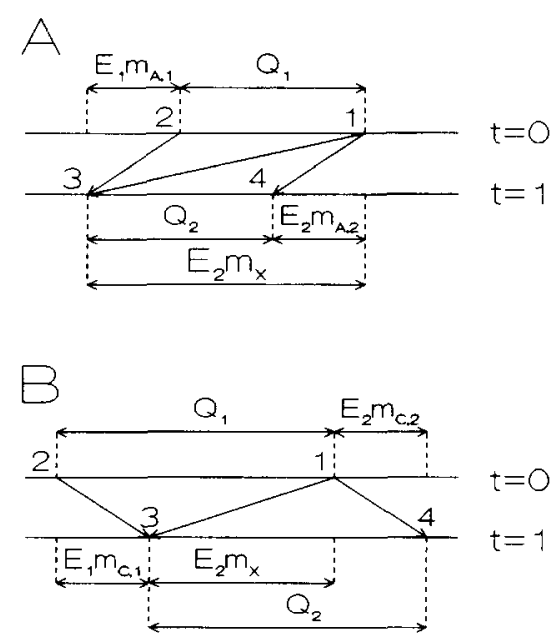

Fig. 5. Migration paths over a zone boundary between segments 1 and 2 for (A) co-ionic species $\mathrm{A}$ and (B) counter ionic species $\mathrm{C}$. For further explanation, see text.

at time $t=0$ will just reach the zone boundary at point 3 at time $t=1$. The distance between point 2 and 3 is $E_{1} m_{\mathrm{A}, 1}$. Co-ions in zone 2 present at point 1 at time $t=0$ move over a distance $E_{2} m_{\mathrm{A}, 2}$ to point 4 at time $t=1$. This means that the co-ions, present in zone 1 at a total concentration $c_{\mathrm{A}, 1}$ at time $t=0$ between the points 1 and 2 will be present between the points 4 and 3 at a total concentration $c_{\mathrm{A}, 2}$ at time $t=1$, i.e. that the amounts of the co-ions $Q_{1}$ and $Q_{2}$ are equal. Therefore the mass balance of the co-ions over the zone boundary will be:

$c_{\mathrm{A}, 1}\left(E_{2} m_{\mathrm{X}}-E_{1} m_{\mathrm{A}, 1}\right)=c_{\mathrm{A}, 2}\left(E_{2} m_{\mathrm{X}}-E_{2} m_{\mathrm{A}, 2}\right)$

or

$c_{\mathrm{A}, 2}=c_{\mathrm{A}, 1} \frac{m_{\mathrm{X}}-\frac{E_{1}}{E_{2}} m_{\mathrm{A}, 1}}{m_{\mathrm{X}}-m_{\mathrm{A}, 2}}$

Identical formulae are obtained if the co-ions have a mobility higher than that of the zone boundary and are valid for both cationic and anionic separations, even in the presence of an EOF.

\section{Mass balance of the counter-ions}

The zone boundary moves in a unit of time from point 1 at time $t=0$ (see Fig. 5B) to point 3 at time 
$t=1$ over a distance $E_{2} m_{\mathrm{X}}$. The counter ions C present at point 2 at time $t=0$, will just reach the zone boundary at point 3 at time $t=1$. The distance between point 2 and 3 is $E_{1} m_{C, 1}$. The counter ions present at point 1 at time $t=0$ will move over a distance $E_{2} m_{\mathrm{C}, 2}$ and will reach point 4 at time $t=1$. All counter ions $C$ present between point 1 and 2 in zone 1 at a total concentration $c_{\mathrm{C}, 1}$ will be present in zone 2 between 3 and 4 at a total concentration $c_{\mathrm{C}, 2}$ at time $t=1$. The amount of counter ions $Q_{1}$ and $Q_{2}$ will be equal and the mass balance of the counter ions $\mathrm{C}$ will be therefore:

$c_{\mathrm{C}, 1}\left(E_{2} m_{\mathrm{X}}+E_{1} m_{\mathrm{C}, 1}\right)=c_{\mathrm{C} .2}\left(E_{2} m_{\mathrm{X}}+E_{2} m_{\mathrm{C}, 2}\right)$

or

$c_{\mathrm{C}, 2}=c_{\mathrm{C}, 1} \frac{m_{\mathrm{X}}+\frac{E_{1}}{E_{2}} m_{\mathrm{C}, 1}}{m_{\mathrm{X}}+m_{\mathrm{C}, 2}}$

\section{Calculation procedure}

The calculation procedure is as follows. All parameters of the BGE can be calculated because its composition is known. For a particular BGE-like zone the concentration of one of the co-ions is assumed. Then the $\mathrm{pH}$ is assumed whereby all $\mathrm{pH}$ dependent parameters such as the effective mobilities can be calculated. The ratio $E_{1} / E_{2}$ is assumed and from the mass balance of one of the co-ions the mobility of the segment considered, $m_{\mathrm{X}}$, can be calculated. From the mass balances of the concen- trations, all other co-ions and counter-ions can be calculated from the concentrations in the preceding segment. Iterating between a high and low value of $E_{1} / E_{2}$ the correct value of $E_{1} / E_{2}$ can be found whereby the EN equation is valid and the correct value of $\mathrm{pH}_{2}$ can be found by iterating over a low and high pH value until Ohm's law is obeyed. This procedure can be followed independently of the number of co-ionic and counter ionic species.

\section{References}

[1] J.L. Beckers, J. Chromatogr. A 693 (1995) 347.

[2] J.L. Beckers, J. Chromatogr. A 696 (1995) 285.

[3] J.L. Beckers, J. Chromatogr. A 741 (1996) 265.

[4] J.L. Beckers, J. Chromatogr. A 764 (1997) 111.

[5] J.L. Beckers, J. Chromatogr. A 679 (1994) 153.

[6] G.J.M. de Bruin, A.C. van Asten, X. Xu, H. Poppe, J. Chromatogr. 608 (1992) 97.

[7] A. Vinther, F.M. Everaerts, H. Soeberg, J. High Resolut. Chromatogr. 13 (1990) 639.

[8] B. Gas, J. Chromatogr. 644 (1993) $16 \mathrm{I}$.

[9] C.L. Colyer, K.B. Oldham, A.V. Sokirko, Anal. Chem. 67 (1995) 3234.

[10] J.J. Cort, J.F. Anacheto, Anal. Chem. 68 (1996) 2155.

[11] T. Wang, R.A. Hartwick, J. Chromatogr. 589 (1992) 307.

[12] B.A. Williams, C. Vigh, Anal. Chem. 68(7) (1996) 1174.

[13] P. Gebauer, P. Bocek, Presented at the 10th International Symposium on CZE and ITP, Prague, L3, 1996, p. 14.

[14] P. Gebauer, P. Bocek, Presented at the 9th International Symposium on High-Performance Capillary Electrophoresis, Anaheim, CA, 1997, Abstracts, p. 70.

[15] F.E.P. Mikkers, Anal. Chem. 69 (1997) 333. 